\title{
The Influence of the Relative Position of the Thiophene and Pyrrole Rings in Donor-Acceptor Thienylpyrrolyl-Benzothiazole Derivatives. A Photophysical and Theoretical investigation
}

\author{
João Pina, ${ }^{* a}$ J. Sérgio Seixas de Melo, ${ }^{a}$ Rosa M. F. Batista, ${ }^{b}$ Susana P.G. Costa ${ }^{b}$ and M. Manuela M. \\ ${ }_{5} \operatorname{Raposo}^{* b}$
}

Received (in $X X X, X X X)$ Xth $X X X X X X X X X 200 X$, Accepted Xth $X X X X X X X X X 200 X$

First published on the web $X$ th $X X X X X X X X X 200 X$

DOI: 10.1039/b000000x

\begin{abstract}
10 A detailed spectroscopic and photophysical study has been carried out on a series of heterocyclic compounds -known to display nonlinear optical properties- consisting on one electron donating thienylpyrrolyl $\pi$-conjugated system functionalized with an electron acceptor benzothiazole moiety. The absorption, emission and triplet-triplet absorption together with all relevant quantum yields (fluorescence, intersystem crossing and internal conversion), excited state lifetimes and the 15 overall set of deactivation rate constants $\left(k_{F}, k_{I C}\right.$ and $\left.k_{I S C}\right)$ were obtained in solution at room (293 $\mathrm{K})$ and low $(77 \mathrm{~K})$ temperature. The optimized ground-state molecular geometries for the compounds together with the prediction of the lowest vertical one-electron excitation energy and the relevant molecular orbital contours for the compounds were also determined using the density functional theory (DFT) at the B3LYP/3-21G* level. The experimental results showed that the

${ }_{20}$ photophysical properties are influenced by the relative position of the pyrrole and thiophene relative to the benzothiazole groups.
\end{abstract}

\footnotetext{
${ }^{a}$ Departamento de Química da Universidade de Coimbra, Rua Larga, 3004-535 Coimbra, Portugal

${ }^{b}$ Centro de Química, Universidade do Minho, Campus de Gualtar, 4710-057 Braga, Portugal
} 


\section{Introduction}

The research for nonlinear optical (NLO) materials has been the focus of intense research in due part to their potential in applications including optical data transmission and 5 information processing. ${ }^{1-5}$ High NLO responses are obtained when the materials possess large molecular hyperpolarizabilities and low optical loss.6, 7 A general approach to obtain materials with non-linear optical properties consists in the synthesis of chromophores involving electron10 donor and electron-acceptor groups linked through a $\pi$ conjugated spacer. The use of organic $\pi$-conjugated systems is particularly relevant in the development of NLO materials since, amongst other properties, they can show large nonlinearities, and display ultra-fast responses, because the 15 electronic polarization is nearly instantaneous. ${ }^{1}$ For these systems, optimization of the electron donor and electron acceptor characteristics of the substituents is needed to obtain maximum nonlinearity at a molecular level. For the $\pi$ conjugating bridge systems, several linear polyenes to various 20 aromatic (heterocyclic) substituents have been used..$^{8-11}$ Included in these, easily delocalized five-membered rings (such as furan and thiophene based $\pi$-conjugated spacers) have proved to increase the hyperpolarizabilities of NLO chromophores. $1,6,7,12,13$ This is in part due to the high 25 chemical and thermal stability together with the displayed good optical properties which allow efficient $\pi$-electron delocalization. ${ }^{12-15}$ Although less investigated, pyrrole containing chromophores as the conjugated bridge, were found to display enhanced NLO properties in comparison with 30 their analogues with furan or thiophene. ${ }^{16}$ This was attributed to the higher electron density in the pyrrole moiety compared to thiophene and furan which led to enhanced NLO effects. ${ }^{17}$,

18 This higher electron density (in the pyrrole ring) can be explained by the different electric dipole moment of pyrrole 35 compared to thiophene and furan, with its direction from the heteroatom to the five-membered ring, thus enhancing the contribution of the $n$ electrons of the nitrogen atom to the $\pi$-system. However, although the results showed that pyrrole moieties are promising building blocks for chromophores with 40 enhanced NLO properties it was concluded that the increase or decrease of the molecular nonlinear activity on heteroaromatic systems depends on the nature of the aromatic rings as well as on the location of these heteroaromatic rings in the system. ${ }^{19,20,21}$

${ }_{45}$ An additional advantage of the use of $\pi$-excessive heteroaromatic groups in the conjugated bridge is that they also act as donor groups.

Having in mind our recent work, concerning the synthesis and photophysical properties of benzothiazole derivatives in 50 conjunction with five membered heterocycles (thiophene and pyrrole $)^{22,23}$ we decided to investigate the effect of the presence and position of electron-rich and electron-defficient heterocycles on the photophysics of these compounds. The present work follows a previous report of the synthesis, the 55 second-order hyperpolarizability $(\beta)$ and thermal stability of 1-(alkyl)aryl-2-(2'-thienyl)pyrroles (acting as $\pi$-electron donors) end-terminated with a benzothiazole group (electron- withdrawing group). ${ }^{24}$ We have previously found that the position of the electron-deficient benzothiazole on the ${ }_{60}$ thienylpyrrolyl system had a marked influence on the nonlinear optical properties. With the present paper, we extend this study to the detailed spectroscopic (singlet and triplet state) and the photophysical properties in solution (at room and low temperature), together with the theoretical

65 investigation (DFT) of the ground- and singlet excited state optimized geometries of these compounds.

\section{Experimental}

The thienylpyrrolyl-benzothiazoles $\mathbf{1 a}$ and $\mathbf{2 a - c}$ were synthesized as elsewhere described. ${ }^{24}$ The solvents were all of 70 spectroscopic or equivalent grade and used without further treatment. Absorption spectra and fluorescence were recorded on a Shimadzu UV-2100 and Horiba-Jobin-Ivon Fluorog 3-22 spectrometers respectively. Phosphorescence measurements were made in methylcyclohexane $(\mathrm{MCH})$ glasses at $77 \mathrm{~K}$ and 75 used the Horiba-Jobin-Ivon Fluorog 3-22 spectrometer equipped with a 1934D phosphorimeter unit and a $150 \mathrm{~W}$ pulsed xenon lamp. All the fluorescence and phosphorescence spectra were corrected for the wavelength response of the system.

${ }_{80}$ The fluorescence quantum yields were measured using as standards terthiophene $\left(\phi_{\mathrm{F}}=0.057\right)$ and quaterthiophene $\left(\phi_{\mathrm{F}}=0.18\right)$ in $\mathrm{MCH} .{ }^{25}$ The fluorescence quantum yields at $77 \mathrm{~K}$ were obtained by comparison with the spectrum at $293 \mathrm{~K}$ run under identical experimental conditions and the $\phi_{\mathrm{F}}$ value was ${ }_{85}$ obtained by assuming that $\mathrm{V}_{77 \mathrm{~K}} / \mathrm{V}_{293 \mathrm{~K}}=0.8 .{ }^{26}$ Phosphorescence quantum yields were obtained using benzophenone in ethanol solution $\left(\phi_{\mathrm{Ph}}=0.84\right)$ as standard. ${ }^{26}$

The molar extinction coefficients $(\varepsilon)$ were obtained from the slope of the plot of the absorption with six solutions of 90 different concentrations $v s$ the concentration (correlation values $\geq 0.999$ ).

Fluorescence decays were measured using a home-built picosecond time correlated single photon counting (TCSPC) apparatus described elsewhere ${ }^{27}$. Fluorescence decays and the 95 instrumental response function (IRF) where collected using 4096 channels, until $5 \times 10^{3}$ counts at maximum were reached. The full width at half maximum (FWHW) of the IRF was about 22 ps and was highly reproducible with identical system parameters. Deconvolution of the fluorescence decays curves 100 was performed using the modulating functions of George Striker. ${ }^{28}$

The experimental setup used to obtain triplet spectra and triplet yields has been described elsewhere. ${ }^{29,} 30$ First-order kinetics was observed for the decay of the lowest triplet state. 105 Special care was taken in determining triplet yields, namely to have optically matched dilute solutions $(a b s \approx 0.2$ in a $10 \mathrm{~mm}$ square cell) and low laser energy $(\leq 2 \mathrm{~mJ})$ to avoid multiphoton and T-T annihilation effects.

The triplet molar absorption coefficients were obtained by the 110 energy transfer method. ${ }^{31}$ The triplet state molar absorption coefficients were determined using naphthalene, $\varepsilon_{\mathrm{T}}=24500 \mathrm{M}^{-}$ ${ }^{1} \mathrm{~cm}^{-1}(415 \mathrm{~nm})$ as triplet energy donor. ${ }^{26}$ The concentrations for the thienylpyrrole-benzothiazoles were $10^{-5} \mathrm{M}$ and they were dissolved in $1 \mathrm{mM}$ methylcyclohexane solution of 
naphthalene. Before experiments, all solutions were degassed with nitrogen for 30 minutes and sealed.

The $\phi_{\mathrm{T}}$ values were obtained by comparing the $\Delta$ O.D. at 525 $\mathrm{nm}$ of a benzene solution of benzophenone (bzph, the 5 standard) and of the compound ( $c p$, optically matched at the laser wavelength) using the equation: ${ }^{32}$

$\phi_{T}^{c p}=\frac{\varepsilon_{T T}^{b z p h}}{\varepsilon_{T T}^{c p}} \cdot \frac{\Delta O D_{\max }^{c p}}{\Delta O D_{\max }^{b z p h}} \cdot \phi_{T}^{b z p h}$

10 Room-temperature singlet oxygen phosphorescence was detected in a Horiba-Jobin-Ivon SPEX Fluorog 3-22 equipped with a Hamamatsu R5509-42 photomultiplier cooled to $193 \mathrm{~K}$ in a liquid nitrogen chamber (Products for Research model PC176TSCE-005) The use of a Schott RG1000 filter was 15 essential to eliminate from the infrared signal all of the first harmonic contribution of the sensitizer emission in the region below $850 \mathrm{~nm}$. The sensitized phosphorescence emission spectra of singlet oxygen from optically matched solutions of the samples and that of reference were obtained in identical 20 experimental conditions. The singlet oxygen formation quantum yield was then determined by comparing the integrated area under the sensitized emission spectra of singlet oxygen of the samples solutions $\left(\int I(\lambda)^{c p} d \lambda\right)$ and that of the reference solution $\left(\int I(\lambda)^{r e f} d \lambda\right)$ and applying equation 2 .

25

$$
\phi_{\Delta}^{c p}=\frac{\int I(\lambda)^{c p} d \lambda}{\int I(\lambda)^{r e f} d \lambda} \phi_{\Delta}^{r e f}
$$

with $\phi_{\Delta}^{\text {ref }}$ the singlet oxygen formation quantum yield of the reference compound. 1H-Phenalen-1-one in toluene $\left(\phi_{\Delta}=\right.$ 30 0.93) was used as standard. ${ }^{33}$

The ground state molecular geometry was optimized using the density functional theory (DFT) by means of the Gaussian 03 program $^{34}$, under B3LYP/3-21G* level ${ }^{35,}{ }^{36}$. Optimal geometries were determined on isolated entities in a vacuum 35 and no conformation restrictions were imposed. For the resulting optimized geometries time dependent DFT calculations (using the same functional and basis set as those in the previously calculations) were performed to predict the vertical electronic excitation energies. The excited-state 40 geometry for was optimized using the Hartree-Fock based single-excitation restricted configuration interaction (RCIS) ${ }^{37}$ method with the $3-21 \mathrm{G}^{*}$ basis set. Molecular orbital contours were plotted using Molekel 5.3. ${ }^{38}$
45 Important features that will be considered in this study are the changes in the spectroscopic and photophysical properties induced by $(i)$ the position of the benzothiazole moiety (linked to position 2- of the pyrrole or the thiophene ring) and (ii) the substitution on the nitrogen atom of the pyrrole ring (see ${ }_{50}$ Scheme 1). The structures of the investigated compounds are depicted in Scheme 1.<smiles>[R]n1c(-c2cccs2)ccc1-c1nc2ccccc2s1</smiles>

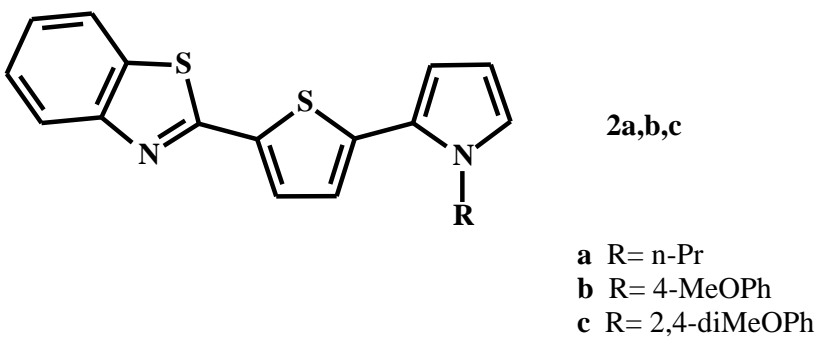

Scheme 1

\section{Singlet state}

${ }_{55}$ Figure 1 presents the absorption and fluorescence emission spectra of the investigated thienylpyrrolyl-benzothiazole 1-2 derivatives in methylcyclohexane $(\mathrm{MCH})$ solution at room and low temperature. These display absorption bands and wavelength maxima (Table 1) which are similar to those 60 reported for the thienyl-benzothiazole derivatives, particularly when the comparison is made between $\mathbf{2 a}$ (and derivatives $\mathbf{2 b}$ and 2c) and the benzothiazole-bithienyl derivative (BZT2a) ${ }^{39}$, showing that in terms of spectral characteristics the substitution of a thiophene with a pyrrole ring has no 65 significant changes in the properties displayed by these compounds.

\section{Results}


Table 1- Spectroscopic properties for the thienylpyrrolyl-benzothiazoles in toluene and methylcyclohexane at $293 \mathrm{~K}$ and $77 \mathrm{~K}$.

\begin{tabular}{|c|c|c|c|c|c|c|c|c|c|}
\hline Compound & $\begin{array}{c}\lambda_{\max }^{S_{1} \leftarrow S_{0}} \\
(\mathrm{~nm}) \\
293 \mathrm{~K}\end{array}$ & $\begin{array}{c}\lambda_{\max }^{S_{1} \leftarrow S_{0}} \\
(\mathrm{~nm}) \\
(\mathrm{DFT})\end{array}$ & $\begin{array}{c}\lambda_{\max }^{S_{1} \leftarrow S_{0}} \\
(\mathrm{~nm}) \\
77 \mathrm{~K}\end{array}$ & $\begin{array}{c}\lambda_{\max }^{S_{1} \rightarrow S_{0}} \\
(\mathrm{~nm}) \\
293 \mathrm{~K}\end{array}$ & $\begin{array}{c}\lambda_{\max }^{S_{1} \rightarrow S_{0}} \\
(\mathrm{~nm}) \\
77 \mathrm{~K}\end{array}$ & $\begin{array}{c}\lambda_{\max }^{T_{1} \rightarrow T_{n}} \\
(\mathrm{~nm}) \\
293 \mathrm{~K}\end{array}$ & $\begin{array}{c}\varepsilon_{S S^{a}} \\
\left(M^{-1} \mathrm{~cm}^{-1}\right)\end{array}$ & $\begin{array}{c}\varepsilon_{\mathrm{TT}}^{\mathrm{a}} \\
\left(\mathrm{M}^{-1} \mathrm{~cm}^{-1}\right)\end{array}$ & $\begin{array}{c}\Delta_{\mathrm{Ss}^{\mathrm{b}}} \\
\left(\mathrm{cm}^{-1}\right) \\
293 \mathrm{~K}\end{array}$ \\
\hline $\begin{array}{c}1 \mathrm{a} \\
(\mathrm{MCH})\end{array}$ & $\begin{array}{c}355 \\
(353)\end{array}$ & 341 & $(362)$ & $\begin{array}{c}410,432 \\
(402,425,450)\end{array}$ & $(397,419,442)$ & 560 & 28600 & $(9600)$ & $\begin{array}{c}3779 \\
(3453)\end{array}$ \\
\hline $\begin{array}{c}2 \mathrm{a} \\
(\mathrm{MCH})\end{array}$ & $\begin{array}{c}380 \\
(375)\end{array}$ & 381 & $(385)$ & $\begin{array}{r}455, \underline{473} \\
(432, \underline{458})\end{array}$ & $(430, \underline{455})$ & 480 & 18100 & $(6500)$ & $\begin{array}{c}5174 \\
(4833)\end{array}$ \\
\hline $\begin{array}{c}2 \mathrm{~b} \\
(\mathrm{MCH})\end{array}$ & $\begin{array}{c}386 \\
(380)\end{array}$ & 385 & $(390)$ & $\begin{array}{r}450, \overline{470} \\
(429, \underline{455})\end{array}$ & $(427, \underline{456}, 485)$ & 475 & 12100 & $(8850)$ & $\begin{array}{c}4630 \\
(4338)\end{array}$ \\
\hline $\begin{array}{c}2 \mathrm{c} \\
(\mathrm{MCH})\end{array}$ & $\begin{array}{c}392 \\
(387)\end{array}$ & 388 & (397) & $\begin{array}{c}452, \underline{473} \\
(435, \underline{460})\end{array}$ & $(442, \underline{465})$ & 480 & 23700 & $(8200)$ & $\begin{array}{c}4369 \\
(4101)\end{array}$ \\
\hline
\end{tabular}

${ }^{\mathrm{a}}$ singlet $\left(\varepsilon_{\mathrm{SS}}\right)$ and triplet $\left(\varepsilon_{\mathrm{TT}}\right)$ molar extinction coefficients

${ }^{\mathrm{b}}$ Stokes-shift

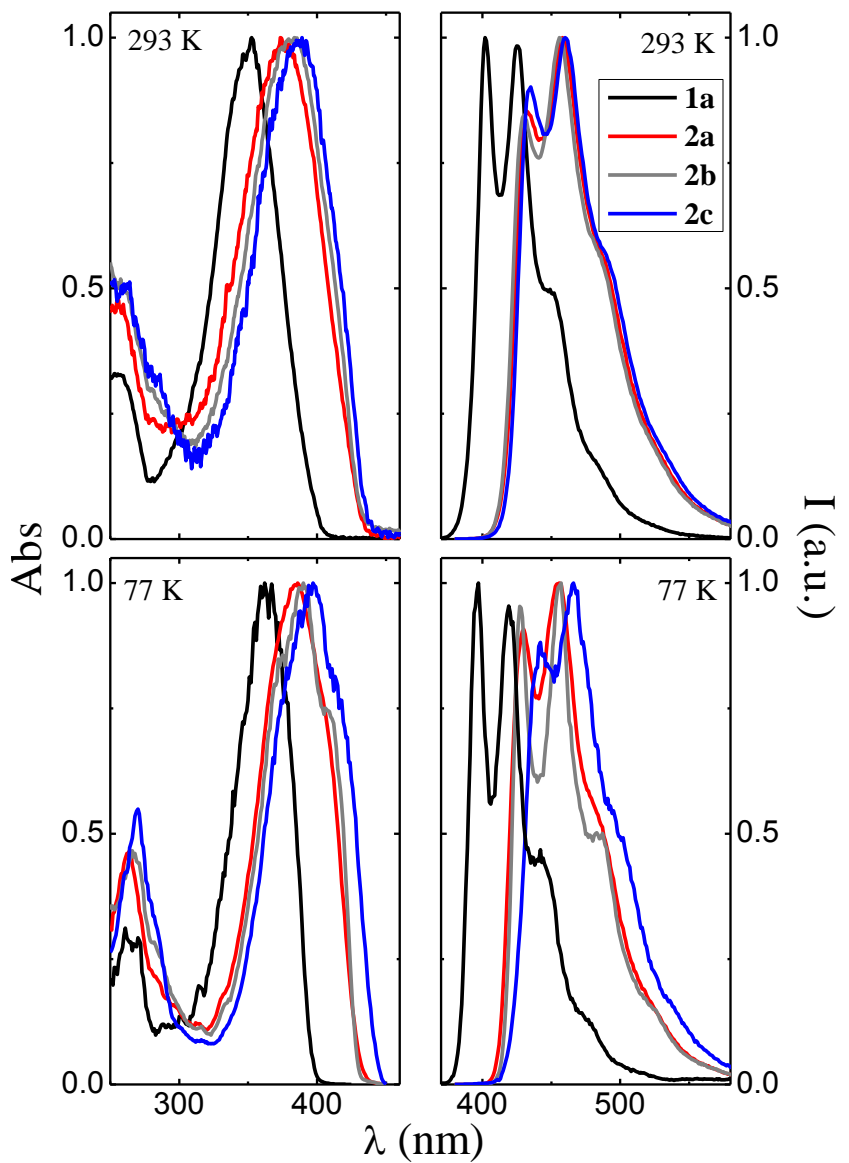

Figure 1- Normalized absorption and fluorescence emission spectra for 5 the thienylpyrrolyl-benzothiazoles 1-2 in methylcyclohexane solution at $293 \mathrm{~K}$ and $77 \mathrm{~K}$.

In order to get more insight on the electronic properties of the compounds the ground state geometry of these was optimized at the DFT/B3LYP/3.21G* level (Figure 2). In addition for $10 \mathbf{2 a}$, the singlet excited state geometry was optimized using the RCIS/3.21G* method and basis set (Figure 3).

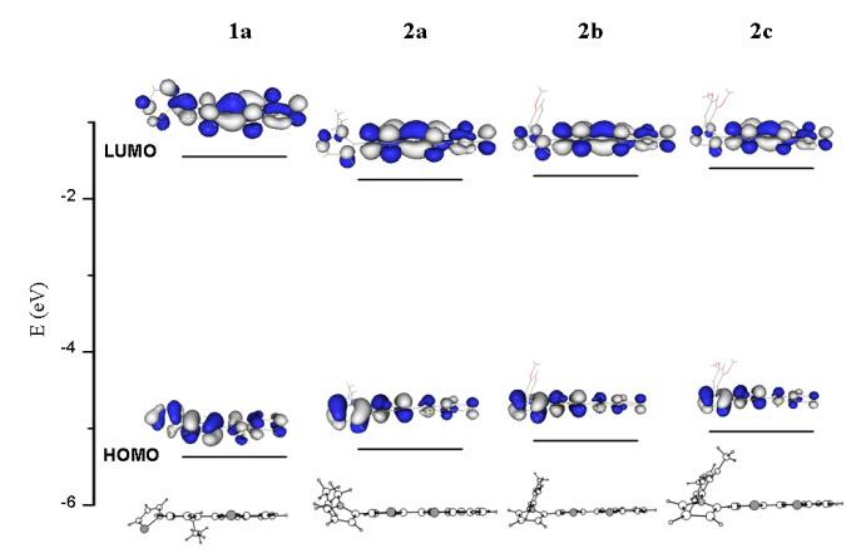

Figure 2- B3LYP/3-21G* DFT optimized ground-state molecular structures for the thienylpyrrolyl-benzothiazoles 1-2 together with the relevant molecular orbital contours around the band gap.
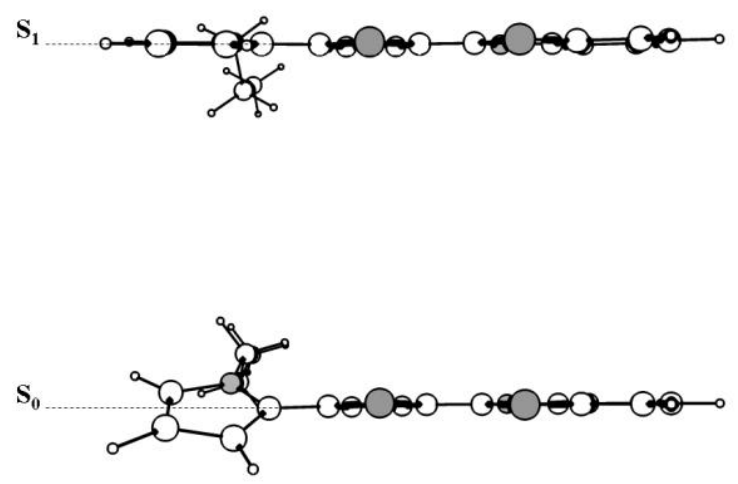

Figure 3- DFT//B3LYP/3-21G* optimized lowest lying singlet $\left(\mathrm{S}_{0}\right)$ and the $\mathrm{HF} / / \mathrm{RCIS} / 3-21 \mathrm{G}^{*}$ singlet excited state $\left(\mathrm{S}_{1}\right)$ geometries for compound 2a.

${ }_{20}$ Fluorescence decays (collected at the emission wavelength maximum) were measured in solution at room temperature and were all seen to fit to monoexponential decay laws (see Figure 4). 
Table 2- Photophysical properties including quantum yields (fluorescence, $\phi_{\mathrm{F}}$, internal conversion, $\phi_{\mathrm{IC}}$, triplet formation, $\phi_{\mathrm{T}}$, and sensitized singlet oxygen formation, $\left.\phi_{\Delta}\right)$, lifetimes $\left(\tau_{\mathrm{F}}, \tau_{\mathrm{T}}\right)$, rate constants $\left(k_{F}, k_{N R}, k_{I C}, k_{I S C}\right)$ for the thienylpyrrolyl-benzothiazoles in toluene and methylcyclohexane at $293 \mathrm{~K}$ and 77 K.

\begin{tabular}{|c|c|c|c|c|c|c|c|c|c|c|c|}
\hline Compound & $\begin{array}{c}\phi_{\mathrm{F}} \\
293 \mathrm{~K}\end{array}$ & $\begin{array}{c}\tau_{\mathrm{F}} \\
(\mathrm{ns}) \\
293 \mathrm{~K}\end{array}$ & $\begin{array}{c}\phi_{\mathrm{F}} \\
77 \mathrm{~K}\end{array}$ & $\begin{array}{c}\phi_{\mathrm{IC}} \\
293 \mathrm{~K}\end{array}$ & $\phi_{\mathrm{T}}$ & $\phi_{\Delta}$ & $\tau_{\mathrm{T}}(\mu \mathrm{s})$ & $\begin{array}{c}k_{F} \\
\left(\mathrm{~ns}^{-1}\right) \\
293 \mathrm{~K}\end{array}$ & $\begin{array}{c}k_{N R} \\
\left(\mathrm{~ns}^{-1}\right) \\
293 \mathrm{~K}\end{array}$ & $\begin{array}{c}k_{I C} \\
\left(\mathrm{~ns}^{-1}\right) \\
293 \mathrm{~K}\end{array}$ & $\begin{array}{c}k_{I S C} \\
\left(\mathrm{~ns}^{-1}\right) \\
293 \mathrm{~K}\end{array}$ \\
\hline $\begin{array}{c}1 \mathrm{a} \\
(\mathrm{MCH})\end{array}$ & $\begin{array}{c}0.17 \\
(0.21)\end{array}$ & 0.540 & $(0.18)$ & 0.20 & 0.63 & 0.61 & 7.75 & 0.315 & 1.54 & 0.380 & 1.17 \\
\hline $\begin{array}{c}2 \mathrm{a} \\
(\mathrm{MCH})\end{array}$ & $\begin{array}{c}0.70 \\
(0.69)\end{array}$ & 2.03 & $(0.43)$ & 0.12 & 0.18 & 0.11 & 6.06 & 0.345 & 0.148 & 0.059 & 0.089 \\
\hline $\begin{array}{c}2 \mathrm{~b} \\
(\mathrm{MCH})\end{array}$ & $\begin{array}{c}0.73 \\
(0.66)\end{array}$ & 2.01 & $(0.42)$ & 0.16 & 0.11 & 0.11 & 25.0 & 0.363 & 0.134 & 0.080 & 0.055 \\
\hline $\begin{array}{c}2 \mathrm{c} \\
(\mathrm{MCH})\end{array}$ & $\begin{array}{c}0.69 \\
(0.67)\end{array}$ & 2.00 & $(0.44)$ & 0.19 & 0.12 & 0.10 & 16.5 & 0.345 & 0.155 & 0.095 & 0.060 \\
\hline
\end{tabular}

$$
k_{F}=\frac{\phi_{F}}{\tau_{F}} ; k_{N R}=\frac{1-\phi_{F}}{\tau_{F}} ; k_{I C}=\frac{1-\phi_{F}-\phi_{T}}{{ }^{\tau} F} ; k_{I S C}=\frac{\phi_{T}}{\tau_{F}} ; \phi_{I C}=1-\phi_{F}-\phi_{T}
$$

(for more details see experimental section).

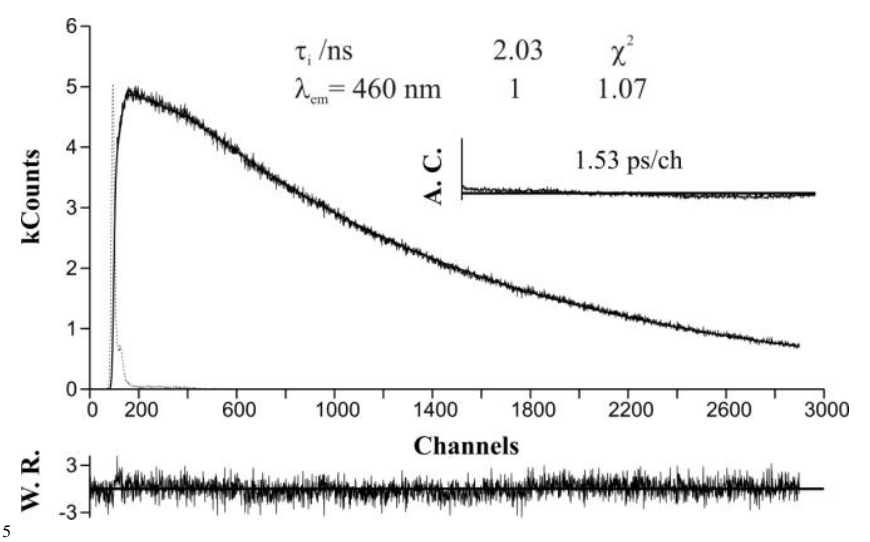

Figure 4- Fluorescence decay for compound 2a in toluene at 293 K. For a better judgment of the quality of the fits, autocorrelation functions (A.C.), weighted residuals (W.R.) and chi-square values $\left(\chi^{2}\right)$ are also present as insets. The dashed lines in the decays are the pulse instrumental response.

\section{Triplet State}

The triplet states of the oligomers were characterized from the transient triplet-triplet absorption spectra in toluene solution at $293 \mathrm{~K}$ (Figure 5). In addition to ground state depletion at shorter wavelengths, the spectra show a broad and intense 15 triplet absorption in the 410-700 nm region (see Figure 5A).

For the thienylpyrrolyl-benzothiazoles phosphorescence was also investigated in methylcyclohexane glasses at $77 \mathrm{~K}$ and with our available current experimental setup we were only able to detect phosphorescence for compound 1a. In this case 20 a structured emission band with a shoulder at $575 \mathrm{~nm}$ and maxima at $610 \mathrm{~nm}$ was observed (see Figure 5B). Compound 1a presents a low phosphorescence quantum yield $\left(\phi_{\mathrm{Ph}}=\right.$ 0.005 ) in agreement to what was previously found for short thiophene oligomers, ${ }^{25,29,40,41}$ thienyl-pyrrol oligomers ${ }^{42}$ and 25 oligothienyl-imidazole ${ }^{43}$ derivatives. The phosphorescence lifetime $\left(\tau_{\mathrm{Ph}}\right)$ for this compound was found to be $15 \mathrm{~ms}$, see inset in Figure 5B.

Singlet oxygen quantum yields were also obtained by comparing the sensitized emission spectra from singlet 30 oxygen, obtained in optically matched solutions of the samples and that of the reference $1 H$-phenalen-1-one, Table 2

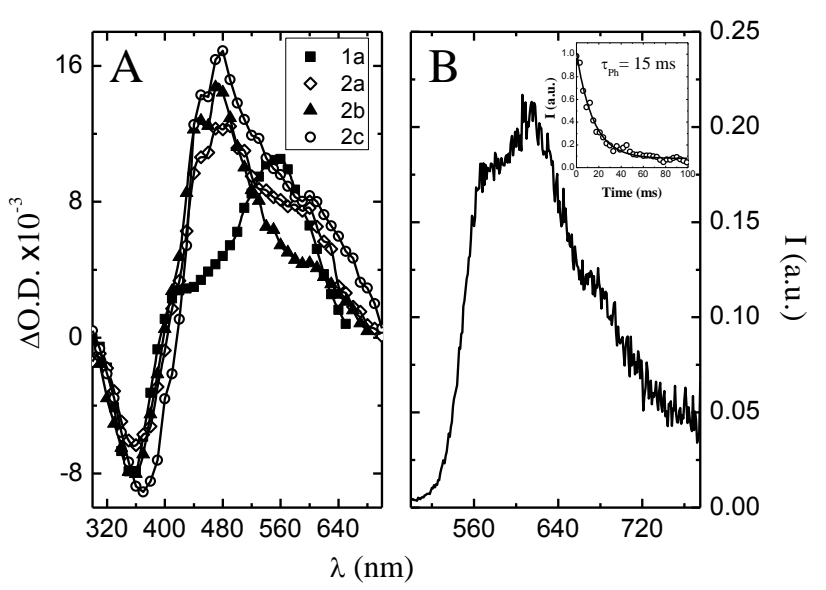

Figure 5- (A) Transient triplet-triplet absorption spectra for the 35 thienylpyrrolyl-benzothiazoles in toluene at $293 \mathrm{~K}$. (B) Phosphorescence emission spectra for compound 1a in MCH solution at $77 \mathrm{~K}$. The phosphorescence emission decay is also present as inset.

\section{Discussion}

\section{Spectroscopic behaviour}

40 The absorption spectra of the thienylpyrrolyl benzothiazoles are broad and devoid of vibrational structure. This behavior is consistent with the fact that the degree of rotational freedom around the thiophene-pyrrol, thiophene-benzothiazole and pyrrol-benzothiazol allows the existence of an ensemble of 45 conformers in the ground-state leading to a broad (overlap of these multiple conformers) absorption. The placement of the benzothiazole moiety on the thiophene heterocycle on the thienylpyrrolyl system (2a), when compared to the derivative bearing the benzothiazole unit at the pyrrole ring (1a), leads 50 to a red-shift in the absorption maxima in solution at $293 \mathrm{~K}$ by $\approx 25 \mathrm{~nm}$ (Table 1 ). This behaviour can be explained by a more extensive electron delocalization (increased intramolecular electron-transfer from the donor to the electron-acceptor group) with $\mathbf{2 a}^{24}$ which in turn leads to an increase in 55 hiperpolarizability when going from $1 \mathbf{a}\left(64 \times 10^{-30}\right.$ esu) to $\mathbf{2 a}$ $\left(\approx 890 \times 10^{-30} \mathrm{esu}\right)$. This is a well-known property of materials 
showing NLO properties ${ }^{44}$ and was previously reported for benzoimidazoles- ${ }^{21}$, benzothiazoles $-{ }^{24}$ and dicyanovinyl- ${ }^{20}$ substituted thienylpyrroles derivatives where it was observed that the increase in the hiperpolarizability values is 5 accompanied by an increase in the absorption wavelength maxima. This observation is in agreement with previous studies where it was concluded that the increase (or decrease) of the molecular NLO activity on heteroaromatic systems is related with the nature of the aromatic rings and on the

10 location of these heteroaromatic chromophores in the systems. ${ }^{19,24,45}$ In our particular case the decrease in hiperpolarizability, when the benzothiazole unit is connected to the pyrrole (1a), indicates that the pyrrole unit is not as good $\pi$-conjugated bridge as thiophene. This is due to the fact, 15 that the pyrrole unit is the most electron-rich five-membered heteroaromatic ring (thus displaying higher aromaticity than the thiophene chromophore) and can counteracts the electronwithdrawing effect of the benzothiazole unit, hindering the electron delocalization. ${ }^{20,24,45}$.

${ }_{20}$ For compounds 2a-c replacement from alkyl to aryl substituents in the pyrrol moiety induces a slight red-shift $(\approx 12 \mathrm{~nm})$ in the absorption wavelength maxima.

Contrary to the absorption band, the fluorescence emission spectra display vibrational structure thus showing that 25 different geometries are adopted in the ground- and singlet excited-state. In agreement with this behavior are the large Stokes-shift values $\left(\Delta_{\mathrm{SS}}\right.$, Table 1$)$ found for the compounds under study. More detail from the ground and excited states can be obtained from the analysis of the DFT calculations. ${ }_{30}$ From the ground-state optimized geometries (DFT calculations) it was seen that for compound 1a a planar conformation is adopted by the pyrrolyl-benzothiazole moieties and the terminal thienyl unit present a dihedral angle of $\approx 50^{\circ}$ with respect to the planar backbone (Figure 2). For 35 compounds 2a-c a similar planar structure was found for the thienyl-benzothiazoles cromophores and again the endterminal unit (pyrrolyl) is slightly twisted, displaying a dihedral angle of $\approx 35^{\circ}, \mathbf{2 a}$, and $\approx 25^{\circ}$ for compounds $\mathbf{2 c}$ and $\mathbf{2 d}$ (Figure 2). The shorter conjugation length found for $\mathbf{5 a}$ can be 40 explained by the more twisted (higher dihedral angle) end terminal thienyl group that acts as a conjugation barrier when compared to compounds $\mathbf{2 a - c .}$

From the TDDFT calculations on the previously optimized ground-state geometries it was possible to predict the lowest 45 vertical one-electron excitation energy (Table 1). The predicted values $341 \mathrm{~nm}, \mathbf{1 a}, 381 \mathrm{~nm}, \mathbf{2 a}, 385 \mathrm{~nm}, \mathbf{2 b}$, and 388 $\mathrm{nm}, \mathbf{2 c}$, are in good agreement with the experimental values in solution (Table 1) which gives support for the calculated molecular geometries. Also worth noting is the fact that the 50 calculated wavelength maxima, and consequently the decrease in the HOMO-LUMO energy difference, upon going from 1a to 2a accounts for the spectral red-shift observed in the absorption wavelength maxima (see Figures 1 and 2).

The excited-state geometry was optimized for $\mathbf{2 a}$ and it was 55 seen that a total planarization of the compound backbone was achieved (Figure 3). This, together with the analysis of the relevant molecular orbital contours (Figure 2), where it was seen that going from the HOMO to the LUMO of the compounds a marked increase in the electron density cloud 60 around the $\mathrm{C}-\mathrm{C}$ bonds connecting the thienyl, pyrrolyl and benzothiazole moieties is observed, shows that a quinoidaltype structure should be adopted in the excited state. TDDFT calculation were performed on the previously optimized excited-state geometry allowing the determination of the 65 vertical radiative transition between the excited- $\left(S_{1}\right)$ and ground-state $\left(S_{0}\right)$. The theoretical value $(423 \mathrm{~nm})$ found is in good agreement with the experimental fluorescence wavelength maxima found for this compound (see Table 1) thus giving, once again, support for the calculated geometry.

${ }_{70}$ Upon going to low temperature a slight increase in vibrational resolution was seen in the absorption and emission spectra. Contrary to what is observed in absorption where $a \approx 10 \mathrm{~nm}$ red-shift was observed when going from $293 \mathrm{~K}$ to $77 \mathrm{~K}$ for the emission band no significant changes were found (see Table 1

75 and Figure 1) thus indicating that similar geometries are adopted (quinoidal-like) in the excited state at $293 \mathrm{~K}$ and 77 K. Similar behavior was reported previously for mixed furanpyrrole-thiophene containing oligomers ${ }^{42}$ and was attributed to a decrease of the relative population of more twisted 80 conformers in the ground-state when going from $293 \mathrm{~K}$ to 77 $\mathrm{K}$. In this situation the ground- and excited-state potential energy curves become more vertically aligned such that the vertical transition is more probable to a lower vibrational level, thus resulting in the observed red-shift of the absorption 85 wavelength maxima at $77 \mathrm{~K}$.

\section{Photophysical behaviour}

The photophysical parameters obtained in solution at $293 \mathrm{~K}$ and $77 \mathrm{~K}$ are shown in Table 2 . From the overall data it can be seen that for all the compounds with exception of 1a the 90 radiative decay channel is the main excited-state deactivation channel. For compound 1a, where the benzothiazole moiety is linked to the pyrrolyl unit, a decrease in the fluorescence quantum yield $\left(\phi_{\mathrm{F}}\right)$ at $293 \mathrm{~K}$ when compared to compounds 2a-c, was observed. In this case, the radiationless processes 95 are dominant and from these, the intersystem crossing (which can be seen from the $\phi_{\mathrm{T}}$, and $k_{I S C}$ parameters in Table 2) is the preferred pathway for the excited-state decay. It is interesting to note that both the photophysical and spectroscopic properties of compound 1a are similar to the analogue thienyl100 pyrrolyl-thienyl (SNS) oligomer. ${ }^{42}$ A potential explanation for the observed behavior is that the less efficient delocalization of $\pi$-electrons seen for 1 a (influenced by the position of the pyrrole ring) induces a similar conjugation segment to that of SNS, and as consequence, 1a retains the characteristic 105 photophysical properties of SNS. On the contrary, for $\mathbf{2 a - c}$ because of the higher charge-transfer character in the compounds there is more involvement of the benzothiazole unit, thus enhancing the fluorescence excited-state deactivation channel. The comparison with the bithienyl110 benzothiazole (BzT2a) ${ }^{39}$ and $2 \mathbf{a}$ shows that the substitution of a thiophene with a pyrrole ring increases the radiative channel. Indeed for BzT2a the quantum yields are $\phi_{\mathrm{F}}=0.31$, $\phi_{\mathrm{T}}=0.52$ and $\phi_{\mathrm{IC}}=0.17^{39}$, whereas with 2a (Table 2) $0.7,0.18$ and 0.12 respectively, thus showing that, going from BZT2a 115 to $2 \mathbf{a}$ the increase in fluorescence occurs with the concomitant 
decrease of the intersystem crossing process. For 1a the low phosphorescence quantum yield and the high intersystemcrossing value indicate that the radiationless channel is the main route for the triplet state decay. In this case, from the 5 onset of the phosphorescence emission band it was possible to estimate the triplet energy of $1 \mathbf{a}(2.30 \mathrm{eV})$. From this and the singlet energy $(3.18 \mathrm{eV}$, taken from the intersection between the normalized absorption and emission spectra) it was obtained the singlet-triplet energy splitting, $\Delta \mathrm{E}_{\mathrm{S} 1-\mathrm{T} 1}=0.88 \mathrm{eV}$.

10 The triplet energy value obtained is similar to the value found for the SNS oligomer $(2.25 \mathrm{eV}) .^{42}$

Upon cooling to $77 \mathrm{~K}$ a decrease in the $\phi_{\mathrm{F}}$ values was seen (again the exception was 1a). A similar decrease in $\phi_{\mathrm{F}}$ when going from $293 \mathrm{~K}$ to $77 \mathrm{~K}$ was previously reported for the 15 thienyl-benzothiazoles ${ }^{39}$ derivatives but contrast with the behavior of thiophene ${ }^{25}$ and mixed furan-pyrrole-thiophene ${ }^{42}$ oligomers where an increase or constancy of this value is generally observed. An explanation to the observed behavior resides, as previously discussed, in the fact that at $77 \mathrm{~K}$ the

20 emission results from an excited-state with the same geometry and energy that at $293 \mathrm{~K}$ but to a more planar ground-state (with higher energy at $77 \mathrm{~K}$ compared to $293 \mathrm{~K}$ ). The better overlap between the $S_{0}$ and $S_{1}$ potential energy curves and the decrease in energy between the two states should promotes a

25 better coupling between the radiationless modes of the excited- and ground-state thus enhancing the non-radiative decay channel with the concomitant decrease in $\phi_{\mathrm{F}}$ at $77 \mathrm{~K}$.

Fluorescence lifetimes $\left(\tau_{\mathrm{F}}\right)$ collected in solution at $293 \mathrm{~K}$ did not reveal the presence of additional fast decay components 30 that could be attributed to fast relaxation processes in the excited state (conformational relaxation or energy migration) thus in agreement with the existence of a rigid quinoidal-like structure in the excited state.

From the overall photophysical parameters (quantum yields 35 and lifetimes) the rate constants for all the decay processes can be obtained. The radiative rate constants $\left(k_{F}\right)$, for all the compounds (including 1a) present a approximately constant value $\left(0.315-0.363 \mathrm{~ns}^{-1}\right)$ thus showing that the decrease in $\phi_{\mathrm{F}}$ for compound 1a is not due to a decrease of this parameter but 40 to an effective increase in the intersystem-crossing rate constant, $k_{I S C}\left(1.17 \mathrm{~ns}^{-1}\right.$ for $\mathbf{1 a}$ versus $0.055-0.089 \mathrm{~ns}^{-1}$ for $\mathbf{2 a -}$ c).

Singlet oxygen was detected by its characteristic phosphorescence following triplet energy transfer from the 45 compounds. The quantum yields for singlet oxygen formation are very close to the quantum yields for triplet formation thus providing support for the calculated latter values and showing that the sensitization of molecular singlet oxygen is very efficient $\left(\mathrm{S}_{\Delta}=\phi_{\Delta} / \phi_{\mathrm{T}} \approx 1\right)$.

${ }_{50}$ It is also worth noting that the different alkyl chain at position 1 of the pyrrole ring has no significant influence in the spectral and photophysical properties of the compounds (2a, $\mathbf{2 b}$ and $\mathbf{2 c}$ ), see Tables 1 and 2 .

\section{Conclusions}

${ }_{55}$ We have investigated the spectroscopic and photophysical properties of thienylpyrrolyl-benzothiazole derivatives in solution at $293 \mathrm{~K}$ and $77 \mathrm{~K}$. It is shown that the position of the benzothiazole heterocycle on the thienylpyrrolyl system affects the extent of charge-transfer between the donor- and 60 electron-acceptor groups and also induces profound changes in the photophysical properties. At room temperature, in general, placement of the benzothiazole group on the thienyl ring, when compared to the pyrrole ring, significantly enhances the radiative excited-state deactivation channel. This 65 shows that the high fluorescence of the benzothiazole unit in conjugated organic oligomers and polymers can be tuned by the direct linking to the additional chromophoric unit, which in the present case was pyrrole vs. thiophene. In addition it was found that different alkyl chains at the nitrogen atom of 70 the pyrrole ring have no effect on the spectral and photophysical properties of these compounds.

\section{Acknowledgments}

Thanks are due to the Foundation for Science and Technology (FCT-Portugal) for financial support through the Centro de ${ }_{75}$ Química-Universidade do Minho (Project PTDC/QUI/66251/2006). FCT is acknowledged for a postdoctoral grant to J. Pina (SFRH/BPD/65507/2009) and a PhD grant to R. Batista (SFRH/BD/36396/2007). We also thank J. P. B. Santos and N. Gonçalves for some of the preliminary 80 spectral measurements.

\section{References}

1 S. R. Marder, B. Kippelen, A. K. Y. Jen and N. Peyghambarian, Nature, 1997, 388, 845-851.

2 Y. Q. Shi, C. Zhang, H. Zhang, J. H. Bechtel, L. R. Dalton, B. H. 85 Robinson and W. H. Steier, Science, 2000, 288, 119-122.

3 T. Baehr-Jones, M. Hochberg, G. X. Wang, R. Lawson, Y. Liao, P. A. Sullivan, L. Dalton, A. K. Y. Jen and A. Scherer, Opt. Express, 2005, 13, 5216-5226.

4 A. Schneider and P. Gunter, Ferroelectrics, 2005, 318, 83-88.

905 F. Kajzar, K. S. Lee and A. K. Y. Jen, in Polymers for Photonics Applications Ii, 2003, vol. 161, pp. 1-85.

6 M. Q. He, T. M. Leslie, J. A. Sinicropi, S. M. Garner and L. D. Reed, Chem. Mat., 2002, 14, 4669-4675.

7 J. A. Davies, A. Elangovan, P. A. Sullivan, B. C. Olbricht, D. H. ${ }_{95}$ Bale, T. R. Ewy, C. M. Isborn, B. E. Eichinger, B. H. Robinson, P. J. Reid, X. Li and L. R. Dalton, J. Am. Chem. Soc., 2008, 130, 10565 10575.

8 L. R. Dalton, W. H. Steier, B. H. Robinson, C. Zhang, A. Ren, S. Garner, A. T. Chen, T. Londergan, L. Irwin, B. Carlson, L. Fifield, G. 100 Phelan, C. Kincaid, J. Amend and A. Jen, J. Mater. Chem., 1999, 9, 19051920.

9 W. Wu, Z. Zhang and X. Zhang, J. Chem. Res., 2004, 2004, 617-619. 10 A. K. Y. Jen, Y. Q. Liu, L. X. Zheng, S. Liu, K. J. Drost, Y. Zhang and L. R. Dalton, Adv. Mater., 1999, 11, 452-455.

10511 P. Hrobarik, P. Zahradnik and W. M. F. Fabian, Phys. Chem. Chem. Phys., 2004, 6, 495-502.

12 J. M. Hao, M. J. Han, K. P. Guo, Y. X. Zhao, L. Qiu, Y. Q. Shen and X. G. Meng, Mater. Lett., 2008, 62, 973-976.

13 B. K. Spraul, S. Suresh, T. Sassa, M. A. Herranz, L. Echegoyen, T. 110 Wada, D. Perahia and D. W. Smith, Tetrahedron Lett., 2004, 45, 32533256. 
14 K. P. Guo, J. M. Hao, T. Zhang, F. H. Zu, J. F. Zhai, L. Qiu, Z. Zhen, X. H. Liu and Y. Q. Shen, Dyes Pigment., 2008, 77, 657-664.

15 P. Blanchard, J. M. Raimundo and J. Roncali, Synth. Met., 2001, 119, 527-528.

516 Q. Q. Li, C. G. Lu, J. Zhu, E. Fu, C. Zhong, S. Y. Li, Y. P. Cui, J. G. Qin and Z. Li, J. Phys. Chem. B, 2008, 112, 4545-4551.

17 Z. A. Li, Z. Li, C. A. Di, Z. C. Zhu, Q. Q. Li, Q. Zeng, K. Zhang, Y. Q. Liu, C. Ye and J. G. Qin, Macromolecules, 2006, 39, 6951-6961.

18 Z. A. Li, Q. Zeng, Z. Li, S. C. Dong, Z. C. Zhu, Q. Q. Li, C. Ye, C. 10 A. Di, Y. Q. Liu and J. G. Qin, Macromolecules, 2006, 39, 8544-8546.

19 P. R. Varanasi, A. K. Y. Jen, J. Chandrasekhar, I. N. N. Namboothiri and A. Rathna, J. Am. Chem. Soc., 1996, 118, 12443-12448.

20 M. M. M. Raposo, A. Sousa, G. Kirsch, P. Cardoso, M. Belsley, E. D. Gomes and A. M. C. Fonseca, Org. Lett., 2006, 8, 3681-3684.

1521 R. M. F. Batista, S. P. G. Costa, M. Belsley and M. M. M. Raposo, Tetrahedron, 2007, 63, 9842-9849.

22 R. M. F. Batista, S. P. G. Costa and M. M. M. Raposo, Tetrahedron Lett., 2004, 45, 2825-2828.

23 S. P. G. Costa, R. M. F. Batista, P. Cardoso, M. Belsley and M. M. 20 M. Raposo, Eur. J. Org. Chem., 2006, 3938-3946.

24 R. M. F. Batista, S. P. G. Costa, E. L. Malheiro, M. Belsley and M. M. M. Raposo, Tetrahedron, 2007, 63, 4258-4265.

25 R. S. Becker, J. Seixas de Melo, A. L. Maçanita and F. Elisei, J. Phys. Chem., 1996, 100, 18683-18695.

2526 M. Montalti, A. Credi, L. Prodi and M. T. Gandolfi, Handbook of Photochemistry, CRC Press, Boca Raton, 2006.

27 J. Pina, J. Seixas de Melo, H. D. Burrows, A. L. Macanita, F. Galbrecht, T. Bunnagel and U. Scherf, Macromolecules, 2009, 42, 17101719.

3028 G. Stricker, V. Subramaniam, C. A. M. Seidel and A. Volkmer, J. Phys. Chem. B, 1999, 103, 8612.

29 J. Pina, H. D. Burrows, R. S. Becker, F. B. Dias, A. L. Maçanita and J. Seixas de Melo, J. Phys. Chem. B, 2006, 110, 6499-6505.

30 J. Pina, J. S. de Melo, H. D. Burrows, A. Bilge, T. Farrell, M. Forster 35 and U. Scherf, J. Phys. Chem. B, 2006, 110, 15100-15106.

31 R. V. Bensasson, E. J. Land and T. G. Truscott, Excited states and free radicals in biology and medicine, Oxford Science Publications, Oxford, 1993.

32 C. V. Kumar, L. Qin and P. K. Das, J. Chem. Soc.-Faraday Trans. II, 40 1984, 80, 783-793.

33 C. Flors and S. Nonell, Helv. Chim. Acta, 2001, 84, 2533-2539.

34 M. J. Frisch, G. W. Trucks, H. B. Schlegel, G. E. Scuseria, M. A. Robb, J. R. Cheeseman, J. Montgomery, J. A., T. Vreven, K. N. Kudin, J. C. Burant, J. M. Millam, S. S. Iyengar, J. Tomasi, V. Barone, B. 45 Mennucci, M. Cossi, G. Scalmani, N. Rega, G. A. Petersson, H. Nakatsuji, M. Hada, M. Ehara, K. Toyota, R. Fukuda, J. Hasegawa, M. Ishida, T. Nakajima, Y. Honda, O. Kitao, H. Nakai, M. Klene, X. Li, J. E. Knox, H. P. Hratchian, J. B. Cross, V. Bakken, C. Adamo, J. Jaramillo, R. Gomperts, R. E. Stratmann, O. Yazyev, A. J. Austin, R. Cammi, C. ${ }_{50}$ Pomelli, J. W. Ochterski, P. Y. Ayala, K. Morokuma, G. A. Voth, P. Salvador, J. J. Dannenberg, V. G. Zakrzewski, S. Dapprich, A. D. Daniels, M. C. Strain, O. Farkas, D. K. Malick, A. D. Rabuck, K. Raghavachari, J. B. Foresman, J. V. Ortiz, Q. Cui, A. G. Baboul, S. Clifford, J. Cioslowski, B. B. Stefanov, G. Liu, A. Liashenko, P. Piskorz, 55 I. Komaromi, R. L. Martin, D. J. Fox, T. Keith, M. A. Al-Laham, C. Y. Peng, A. Nanayakkara, M. Challacombe, P. M. W. Gill, B. Johnson, W.
Chen, M. W. Wong, C. Gonzalez and J. A. Pople, Gaussian 03, Revision C.02, Gaussian, Inc., Wallingford CT, 2004.

35 A. D. Becke, J. Chem. Phys., 1993, 98, 1372-1377.

6036 M. M. Francl, W. J. Pietro, W. J. Hehre, J. S. Binkley, M. S. Gordon, D. J. Defrees and J. A. Pople, J. Chem. Phys., 1982, 77, 3654-3665.

37 J. B. Foresman, M. Headgordon, J. A. Pople and M. J. Frisch, J. Phys. Chem., 1992, 96, 135-149.

38 S. Portmann and H. P. Luthi, Chimia, 2000, 54, 766-770.

6539 J. Pina, J. Seixas de Melo, H. D. Burrows, R. M. F. Batista, S. P. G. Costa and M. M. M. Raposo, J. Phys. Chem. A, 2007, 111, 8574-8578.

40 S. Rentsch, J. P. Yang, W. Paa, E. Birckner, J. Schiedt and R. Weinkauf, Phys. Chem. Chem. Phys., 1999, 1, 1707-1714.

41 D. Wasserberg, P. Marsal, S. C. J. Meskers, R. A. J. Janssen and D. 70 Beljonne, J. Phys. Chem. B, 2005, 109, 4410-4415.

42 J. Seixas de Melo, F. Elisei and R. S. Becker, J. Chem. Phys., 2002, 117, 4428-4435.

43 J. Pina, J. Seixas de Melo, R. M. F. Batista, S. P. G. Costa and M. M. M. Raposo, J. Phys. Chem. B, 2010 (in press).

7544 D. S. Zyss, Non-linear Optical Properties of Organic Molecules and Crystals, Academic Pr, Orlando, 1987.

45 R. D. Miller, V. Y. Lee and C. R. Moylan, Chem. Mat., 1994, 6, 1023-1032.

80 